\title{
Por dentro de uma sala de aula de física
}

\author{
Adelson Fernandes Moreira \\ Centro Federal de Educação Tecnológica de Minas Gerais \\ Oto Borges \\ Universidade Federal de Minas Gerais
}

\section{Resumo}

Apresentamos os resultados de uma investigação etnometodológica sobre uma sala de aula de física, desenvolvendo uma abordagem descritiva desse ambiente de aprendizagem. Atividades com simulações, exercícios com lápis e papel e experimentação foram combinadas para proporcionar aos alunos ambientes de aprendizagem diferenciados. As interações de alguns grupos de alunos foram gravadas, em áudio e vídeo, e analisadas. Ao compará-las, destacamos e analisamos situações nas quais as interações vivenciadas nos diferentes ambientes contribuíam para a descrição de aspectos característicos da prática de alunos e professor. A produção de narrativas é o principal instrumento de descrição. Identificamos o etnométodo de direcionar as interações para a obtenção da resposta correta. Mostramos como esse procedimento, compartilhado por alunos e professor, interfere nas perguntas dirigidas ao professor e na forma de este exercitar sua escuta no diálogo com os alunos. A sala de aula é caracterizada como um local de ações simultâneas, que ocorrem para além do controle docente. Discutimos a concepção expressiva de objetivo e de atividade como referência para lidar com essa impossibilidade de controle. Chamamos atenção para a diversidade de estilos de conduta dos alunos e analisamos suas implicações. Discutimos, finalmente, as conseqüências de tratarmos a sala de aula como um lugar onde se desenvolve uma prática social específica, especialmente em relação aos obstáculos à transposição, para o seu interior, de resultados de pesquisa que implicam em modificações nessa prática.

\section{Palavras-chave}

Etnometodologia - Ambientes de aprendizagem - Sala de aula Ensino de física.
Correspondência:

Adelson Fernandes Moreira

Rua Botelhos, 28

31210-200 - Belo Horizonte - MG

e-mail: adelson@deii.cefetmg.br 


\title{
Inside a Physics classroom
}

\author{
Adelson Fernandes Moreira \\ Centro Federal de Educação Tecnológica de Minas Gerais \\ Oto Borges \\ Universidade Federal de Minas Gerais
}

\begin{abstract}
We present the results of an ethnomethodological study about a Physics classroom, developing a descriptive approach to this learning environment. Activities involving simulations, pen-andpaper exercises, and experiments were arranged to expose students to various learning environments. The interactions among some groups of students were video- and audio-recorded, and analyzed. When comparing them, we highlight and analyze situations in which the interactions experienced in the different environments contribute to the description of the characteristic features of the practice of teacher and of students. The production of narratives is the main instrument of description. We identify the 'ethnomethod' of directing the interactions to obtain the correct answer. We show how this procedure, shared by teacher and students, interferes with the questions made to the teacher, and in the way the latter exercises the listening in the dialogue with the students. The classroom is characterized as a place of simultaneous actions that occur beyond the teacher's control. We discuss the expressed concepts of objective and activity as a way of dealing with this impossibility of control. We call attention to the diversity of styles of students' conducts, and we analyze its implications. Finally, we discuss the consequences of seeing the classroom as a place where a specific social practice occurs, particularly with respect to the obstacles to the transfer to its interior of the results of researches that imply in modifications to this practice.
\end{abstract}

\section{Keywords}

Ethnomethodology - Learning environments - Physics classroom Teaching of Physics.

Contact:

Adelson Fernandes Moreira

Rua Botelhos, 28

31210-200 - Belo Horizonte - MG

e-mail: adelson@deii.cefetmg.br 
0 diálogo entre os resultados de pesquisa, produzidos nos últimos trinta anos e como esses resultados interferem nas práticas de sala de aula, tem sido objeto de discussão nos encontros de pesquisa da área de educação em ciências. Mortmer (2002) afirma que fazer os resultados de pesquisa chegarem à sala de aula é um compromisso importante na área. Acredita que as pesquisas desenvolvidas no Brasil têm concretizado esse compromisso, muito embora não detalhe com que abrangência e profundidade. Ao tematizar a avaliação da área de pesquisa em educação em ciências e a proposição de uma agenda para o futuro, Mortmer levanta questões que julgamos bastante pertinentes, entre elas: o que a pesquisa em educação em ciências já produziu até o momento que auxilia os professores em sala de aula ou os formuladores de políticas educacionais a tomar decisões práticas reais?

Mortmer argumenta sobre a importância de se abrir a sala de aula, descrever e compreender suas dinâmicas de interação e proporcionar ao professor elementos para refletir sobre sua prática. Sintonizados com essa perspectiva, acreditamos que é preciso melhorar nossa compreensão sobre o que ocorre na sala de aula, ou seja, como professor e alunos conferem estabilidade ao seu contexto de ação, e como essa busca de estabilidade acaba por legitimar obstáculos a práticas de ensino mais inovadoras. Nossa investigação faz uma abordagem descritiva da sala de aula, entendida como uma comunidade de prática.

Com base no trabalho de Roth, Bowen e Mcginn (1999), entendemos que uma comunidade de prática pode ser caracterizada: pelas preocupações correntes dos sujeitos envolvidos; pelos procedimentos rotineiros e padronizados do campo no qual esses sujeitos atuam; o grau de domínio na utilização de técnicas e equipamentos; os recursos de linguagem compartilhados; e os momentos de interrupção do processo quando algo deixa de funcionar seja no campo da comunicação, seja quanto aos resultados esperados de um certo procedimento.
Direcionamos nossa investigação para os procedimentos práticos de alunos e professor com competência para se comunicarem dentro de uma comunidade específica. No contexto da pesquisa, a comunidade específica é a sala de aula e os procedimentos práticos focalizados são aqueles relacionados à interpretação de representações de modelos. A perspectiva de pesquisa adotada é a etnometodologia (Coulon, 1995; Holstein; Gubrium, 1994), tratada no capítulo Etnometodologia, no qual detalharemos o método de levantamento e análise dos dados.

Atividades com simulações, exercícios com lápis e papel e experimentação foram combinados para proporcionar aos alunos ambientes de aprendizagem diferenciados. As interações de alguns grupos de alunos foram gravadas, em áudio e vídeo, e analisadas. Ao compará-las, destacamos e analisamos situações nas quais as interações contribuíam para a descrição de aspectos característicos da prática de alunos e professor. Essa descrição é construída com base em narrativas das situações destacadas. Tal procedimento fundamenta-se em nossos estudos sobre a etnometodologia.

No capítulo Construção de um cenário, apresentamos alguns trechos de narrativa agrupados. Estes constituem núcleos de uma descrição que os ultrapassa, para caracterizar os aspectos que consideramos relevantes nos ambientes pesquisados. Nesse exercício sistemático de descrever, salientamos o etnométodo de direcionar as interações para a obtenção da resposta correta, da explicação correta, em detrimento do processo de sua produção. Destacamos como essa perspectiva, compartilhada por alunos e professor, interfere nas perguntas dirigidas ao professor e na forma de este exercitar sua escuta no diálogo com os alunos. A sala de aula é caracterizada como um local de ações simultâneas, que ocorrem para além do controle docente. Um dos aspectos que não podem ser controlados é a evolução da compreensão do objetivo de uma atividade. Dialogando com uma pesquisa desenvolvida por de 
Sá e Borges (2001), destacamos a importância da atuação do professor, não obstante a impossibilidade do controle sobre o que o aluno faz e a compreensão que tem desse processo a cada momento. Com base em Nespor (2001), propomos uma maneira de conceber uma atividade e seus objetivos. Chamamos atenção para a diversidade de estilos de conduta dos alunos e analisamos suas implicações.

Discutimos, finalmente, as conseqüências de tratarmos a sala de aula como um lugar onde se desenvolve uma prática social específica, especialmente em relação aos obstáculos à transposição, para o seu interior, de resultados de pesquisas que implicam em modificações nessa prática.

\section{Etnometodologia}

A realidade da sala de aula se faz pelo trabalho interpretativo de alunos e professor. A atividade permanente de interpretação do que se faz e do que ocorre produz e organiza as muitas circunstâncias do cotidiano escolar. Holstein e Gubrium (1994) discutem um modelo de interpretação dos fatos sociais, baseado em indivíduos com competência para interagir, que constroem, permanentemente, a ordem social por meio de uma ação interpretativa, contextualizada, contingente e contínua. Essa aproximação, chamada etnometodologia, como indica o nome, focaliza os etnométodos, isto é, os procedimentos práticos cotidianos para criar, sustentar e gerenciar a realidade objetiva. Nossa investigação foi desenvolvida dentro dessa perspectiva.

A análise foi centrada no raciocínio prático, na ação conjunta de alunos e professor, buscando tornar estável seu espaço de trabalho, de aprendizagem e de trocas. Em vez de assumir que os participantes de um grupo partilham explicitamente significados e definições de situações, buscamos desvelar como os sujeitos pesquisados se valem de sua capacidade de interpretar, com a colaboração dos outros participantes de uma interação, para constituir, localmente, um senso de ordem e compreensão da ação em curso. Estruturas sociais são localmente produzidas e sustentadas como ambientes normais, rotineiros. São essas ações cotidianas, tácitas, que engendram a noção errônea de uma realidade objetiva, igual para todos. Cada sala de aula tem componentes que, embora determinados por estruturas mais amplas, presentes dentro e fora da escola, se realizam de modo único, não totalmente previsível, mediante o trabalho interpretativo dos sujeitos que nela atuam (Coulon, 1995).

Se o real é produzido, "de dentro", pelas práticas de interpretação dos membros de um determinado grupo, as circunstâncias sociais vivenciadas por esses sujeitos não são completamente determinadas. A transgressão e a produção de novidades são componentes potenciais dessas circunstâncias. Na perspectiva da etnometodologia, isso implica em duas propriedades essenciais do significado: ele é indicial - dependente do contexto - e é reflexivo contexto e procedimentos de interpretação se constituem mutuamente.

Sem um contexto visível, objetos e eventos têm um significado indeterminado. Seu significado está entrelaçado ao uso ou à vivência dos sujeitos participantes por meio da fala e da interação. A interação, incluindo-se todos os detalhes que a constituem para além da fala gestos, entonação, atitudes de silêncio, movimentos diferenciados com o corpo - confere significado aos objetos e situações. Todos esses elementos constitutivos da interação estão indexados pelo contexto em que ela transcorre. É importante estar atento aos 'índices' que ligam a interação e o contexto.

As atividades de interpretação ocorrem dentro de um certo cenário, são influenciadas pelos recursos materiais e culturais aí presentes e, ao mesmo tempo, focalizam esse mesmo ambiente, constituindo-o pelo ato de interpretar. Atividades de interpretação e contexto refletem-se mutuamente. Quem interpreta dá forma ao objeto interpretado. Por sua vez, as características do objeto e do contexto em que ele se encontra dão forma à interpretação que 
constitui o objeto. Reflexividade e indicialidade são lados opostos de uma mesma moeda. São aspectos inerentes à realidade social. Suas manifestações e conseqüências são temas de pesquisa centrais da etnometodologia.

Ao discutir a reflexividade e a indicialidade da produção de significados em uma interação, Coulon (1995) destaca a importância do vídeo no trabalho de campo. Os documentos em vídeo permitem captar essa dimensão indicial, ajudando a revelar o implícito das interações, contribuindo para a proposição de relações entre as condutas observadas e as estruturas mais gerais.

A visão do prático reflexivo (Schön, 1987) complementa nossa perspectiva de pesquisa. A ação do professor, que pesquisa a sala de aula em que atua, implica num diálogo permanente entre prática pedagógica e prática de investigação. Reconhecendo a distinção entre essas práticas, entendemos que elas se conectam, respectivamente, aos momentos de reflexão na ação e reflexão sobre a ação. Atuando em sala, mobilizamos principalmente aqueles conhecimentos tácitos, que influenciam tanto as ações rotineiras como as decisões que são tomadas sem interromper o transcurso de uma ação. É o domínio da reflexão na ação. Nosso principal instrumento de coleta de dados foi a câmera de vídeo. Os registros em vídeo possibilitaram uma atitude posterior de reflexão sobre a ação, na qual predominou, então, a prática da pesquisa.

\section{Narrativas}

Nosso material empírico compôs-se de registros em áudio e em vídeo das interações ocorridas nos diferentes ambientes de aprendizagem (Quadro 1). As turmas pesquisadas foram divididas em duas subturmas que desenvolveram, em sentidos opostos, a seguinte seqüência de atividades: atividade com experimentos, exercícios com lápis e papel, atividade com simulações. Dois grupos de cada subturma tiveram suas atividades gravadas. Buscamos elementos de comparação em grupos desenvolvendo a mesma seqüência e realizando o mesmo conjunto de atividades em ordem invertida.

Seguindo esse desenho, realizamos gravações das atividades sobre movimento circular uniforme em duas turmas de $1^{\text {a }}$ série do ensino médio. Em uma delas, gravamos ainda uma seqüência sobre composição de velocidades. Cada seqüência foi desenvolvida em seis aulas. Uma vez que a turma era subdividida, cada seqüência resultou em 12 horas/aula de gravações, totalizando 36 horas, metade delas em áudio, metade em áudio e vídeo. Em cada seqüência, o professor das turmas, um dos autores dessa pesquisa, acompanhou uma subturma. Para acompanhar a outra subturma, contou com a colaboração de dois estudantes de licenciatura em Física e de dois professores de Física, colegas de Departamento.

Episódios foram delimitados com base na observação e análise das 36 horas de gravação. Os registros em áudio e vídeo foram observados continuamente, acompanhando a cronologia de gravação. Nessa primeira observação, fizemos destaques registrando sua posição na fita cassete ou de vídeo e construímos narrativas a partir deles. Em cada narrativa, fizemos uma descrição detalhada da situação destacada, das

\begin{tabular}{|c|c|c|c|c|}
\hline \multicolumn{2}{|c|}{ Turmas: $1^{3}$ Série } & Dados & Seqüèncias & $\begin{array}{c}\text { Tempo de Gravação } \\
\text { (Horas/Aula) }\end{array}$ \\
\hline $\begin{array}{l}\text { Subturma 1: } \\
\text { Atividade com experimentos } \\
\text { Exercicio com lápis e papel } \\
\text { Atividade com simulap̧ōes }\end{array}$ & $\begin{array}{l}\text { Subturma } 2 \\
\text { Atividade com simulaçóes; } \\
\text { Exercicio com lápis e papel; } \\
\text { Atividade com experimentos }\end{array}$ & $\begin{array}{l}\text { Em cada subturma, registro } \\
\text { em áudio e video das } \\
\text { athidades de dois grupos }\end{array}$ & $\begin{array}{l}\text { Movimento circular uniforme (mcu) - } 1^{\mathrm{a}} \\
\text { série A } \\
\text { mcu }-1^{1 \mathrm{a}} \text { série B } \\
\text { (6 aulas) } \\
\text { Composição de velocidades }-1^{\mathrm{a}} \text { strie B } \\
\text { (6 aulas) }\end{array}$ & $\begin{array}{c}12 \\
12 \\
12 \\
\text { Total: } 36\end{array}$ \\
\hline
\end{tabular}


razões do destaque e do que nos chamou a atenção. As narrativas foram primeiramente manuscritas em um caderno de notas. Na medida em que se acumulavam essas narrativas, emergiam algumas sinteses e possíveis hipóteses, que também eram registradas com o maior detalhamento possível. Esse processo - assistir às fitas, fazer destaques, construir narrativas foi sistematicamente interrompido, pois se tratava de um longo período de gravações. Ao reiniciarmos o trabalho, todas as anotações anteriores eram relidas, de modo que cada nova etapa recuperava e reconstruía o todo, que ia sendo produzido com a seqüência de narrativas.

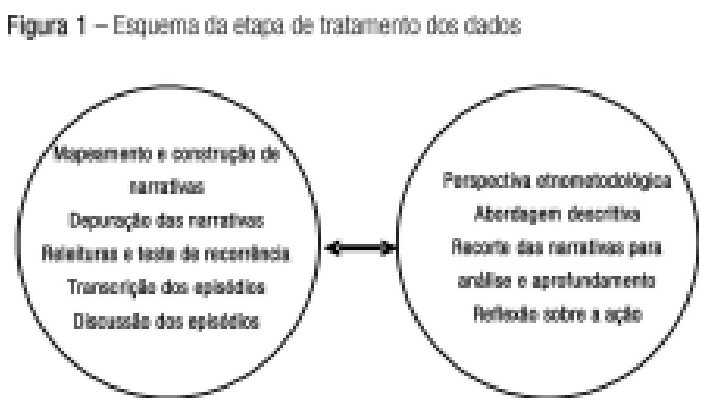

Foi por meio desse processo de elaboração de narrativas, como dados de segunda ordem (Figura 1), que focalizamos as práticas dos sujeitos no ambiente da sala de aula. As ações práticas se realizaram nas atividades de interpretação sobre as representações de modelos de fenômenos físicos. Ao buscarmos a identificação dos etnométodos, procuramos, por um lado, construir o cenário global da aula e, por outro, focalizar as práticas de interpretação dos alunos.

A elaboração de narrativas, entrecortadas por comentários, sínteses e formulação de hipóteses, foi também um exercício da perspectiva do prático reflexivo. As notas produzidas expressam o diálogo, marcado por tensões e convergências, da prática docente - domínio no qual predomina a reflexão-na-ação - com a prática de pesquisa - domínio em que predomina a reflexão sobre a ação.

Um distanciamento dessas anotações permite-nos afirmar que um professor comprometido com seu trabalho e que reflete sistematicamente sobre sua ação realiza em alguma medida ações características de um trabalho de pesquisa; ações estas que resultam na redefinição de objetivos e da forma do 'fazer em sala de aula'. Permite-nos afirmar, ainda, que o pesquisador, que atua como professor e elege diferentes aspectos da sala de aula como objetos de investigação, tem nas suas vivências como professor, do ponto de vista da ética, da relevância e da pertinência, uma rica fonte de crítica sobre os problemas que propõe e sobre seus métodos e objetivos de pesquisa.

Terminada a fase de observação e análise das 36 horas de gravação, o conjunto de narrativas foi lido exaustivamente no sentido de se identificar destaques com características semelhantes, seja do ponto de vista do conteúdo das narrativas, das razões de sua construção ou dos comentários e sínteses que geraram. 0 conjunto de notas foi então digitado no computador. Esse processo caracterizou outra reconstrução. As narrativas foram depuradas e as estruturas dos textos foram ligeiramente melhoradas. Durante essa reconstrução, verificamos mais uma vez a recorrência dos destaques.

0 documento resultante da transcrição das notas no computador, com as narrativas melhor estruturadas, foi lido várias vezes, num esforço de mais uma vez identificar e confirmar elementos de ligação entre as narrativas. Aquelas agrupadas por seus aspectos comuns reconduziram novas averiguações das gravações, agora apenas dos trechos destacados e mapeados. Uma vez confirmados os elementos que ligavam as narrativas, esses trechos foram então delimitados e apresentados como evidências dos elementos da prática social que intentamos caracterizar.

\section{Procedimentos de verificação}

0 espaço de crítica sistemática sobre as descrições e análises produzidas concretizou-se nas reuniões com o co-autor desse trabalho e no grupo de pesquisa do qual fazemos parte. Com o primeiro, descrições e análise eram con- 
trapostas à observação dos episódios registrados em áudio e vídeo. 0 co-autor exercia o papel de juiz da pertinência e qualidade das evidências, das descrições e da análise propostas. Cumprida essa etapa, escrevíamos um relatório transcrevendo as narrativas destacadas, articulando descrição e análise. Esse material foi debatido no grupo de pesquisa. As evidências eram trechos de narrativa e, com isso, procurávamos aferir se as conclusões que retirávamos delas poderiam ser sustentadas do ponto de vista empírico e teórico.

Tais procedimentos não foram realizados para validar os resultados. Tiveram o papel de suportar descrições fundamentadas e as análises decorrentes. Contribuíram para a elaboração de um relatório que explicita as escolhas do pesquisador, que coloca o leitor numa posição de refazer, pelo menos em parte, o caminho trilhado e criticar as escolhas e os resultados obtidos a partir delas.

\section{Construção de um cenário}

Vencida uma primeira etapa do mapeamento com construção de narrativas, tínhamos em mãos um caderno de notas contendo:

- narrativas produzidas logo após a realização das gravações;

- narrativas sobre os destaques feitos durante a observação do material empírico;

- sínteses e hipóteses elaboradas durante a observação do material empírico.

Essa coleção de descrições e reflexões constituiu-se em um conjunto de dados de segunda ordem, com várias possibilidades de exploração como, dentre elas, retratar as ações práticas de alunos e professor e os elementos relativos a indicialidade e reflexividade do contexto pesquisado.

Nesta seção, fazemos a construção do cenário de uma sala de aula mediante o diálogo entre prática docente e prática de pesquisa. Esse cenário compõe-se de sete partes que tematizam: o olhar para uma sala de aula em uma situação de pesquisa; a passividade dos alunos; a simultaneidade das ações; o design como um componente da prática docente; a diversidade de estilos de conduta; e como o livro didático comparece em algumas situações. Esses temas expressam uma síntese da reflexão do pesquisador sobre a sua ação docente e a dos demais atores do ambiente da pesquisa. Alguns deles são enriquecidos com agrupamentos de trechos das narrativas elaboradas. Esses trechos são chamados de notas. Com as notas, exemplificamos, em pequena medida, o tipo de dado de segunda ordem com o qual trabalhamos. Essas notas, as reflexões que suscitaram e o diálogo com trabalhos da área serão apresentados e articulados como um exercício de construção de um cenário. A separação entre cada tema não é estrita. Eles vão se articulando e compondo um cenário, cujos aspectos que consideramos principais serão destacados ao final dessa seção.

\section{- olhar para uma sala de aula em situação de pesquisa}

Nota 1: Descrição realizada após a atividade de resolução de exercícios sobre cinemática do movimento circular uniforme

[...] ainda que eu esteja filmando 'minha' aula, trata-se de um procedimento invasivo. $O$ olhar para os fatos muda. Parecem ficar mais evidentes, no transcurso da atividade, as lacunas proporcionadas pela dinâmica, pela estrutura da atividade, pela minha conduta e pelas condutas dos alunos. A expectativa apresentada no projeto de que, ao longo da aula, predominasse o professor desenvolvendo uma certa ação com os alunos não se concretizou nessa gravação. Ocorreu uma alternância. Ao interagir com os alunos, parece que o professor atuava. Ao observar os grupos, mais a distância, estava presente o pesquisador bastante incomodado com o que via, especialmente com a impossibilidade do controle do que efetivamente faziam os diferentes grupos, 
e a sensação de que o proveito tirado pelos alunos pode ser muito pequeno. É bastante difícil acompanhar 12 duplas, a meu ver, impossível. $O$ acompanhamento está condicionado à solicitação das duplas. Quando falo controle, quero dizer estar ciente, sintonizado com o processo de cada dupla, e isso realmente não é possível.

[...] os alunos parecem gastar muito tempo em tarefas que consideramos, em princípio, triviais, como a reprodução da figura de um automóvel em movimento circular. $O$ traçado da circunferência é problemático, poucos têm compasso, os alunos acabam gastando tempo em detalhes $d a$ figura que não são importantes como, por exemplo, que o automóvel se pareça com um automóvel. A reprodução da figura consumiu grande parte da aula, o que não estava previsto.

A entrada de um equipamento de gravação em uma sala de aula não é um passo trivial da investigação. Requer um tempo de acomodação e de confirmação da efetiva disposição dos alunos em deixar que suas ações sejam registradas. Com o decorrer das aulas, isso foi conseguido. Câmera e gravadores tornaram-se artefatos rotineiros do ambiente da sala de aula, com direito a brincadeiras, recados críticos ao professor e comentários feitos pelos alunos cuja reprodução resultaria em 'quebra de decoro'. Requer também uma logística que não pode ser garantida pelo professor da turma. Os registros em áudio e vídeo exigem preparo e acompanhamento de uma equipe de apoio que teria como único papel garantir a qualidade das gravações.

Assumir a tarefa de pesquisar a própria sala de aula é um processo conflitivo. Inicialmente, acreditávamos que, durante a aula, predominaria a intenção do professor ocupado com a tarefa de ensinar. 0 que foi se revelando e afirmando foi a reciprocidade de papéis, a realimentação contínua dessas duas perspectivas, apurando o olhar crítico do professor e problematizando continuamente o objeto e o foco da pesquisa.

Os objetivos de uma atividade constituem um elemento crítico de seu desenvolvimento. Não é uma tarefa simples articular objetivos, orientação das atividades, disposição dos materiais necessários e tempo de realização da tarefa. Orientações, primeiramente consideradas de execução simples e demandando um tempo pequeno, transformam-se em obstáculos que emperram o desenvolvimento da atividade, requerem um tempo maior e comprometem o alcance dos objetivos propostos.

\section{Como atuar sobre a passividade dos alunos?}

A dupla retratada em uma das narrativas pouco realiza. Não solicita o professor que, embora já tivesse percebido a pouca operatividade desses dois alunos, fica envolvido com os demais que o chamavam e lhe propunham questões. Ao final, o professor aproxima-se da dupla, mas ainda assim não consegue estabelecer um diálogo efetivo, faltando-lhe uma atitude de escuta para compreender a real questão dos alunos. Enquanto uma parcela da turma está envolvida, com dificuldades, e pergunta, solicitando o professor, há alunos passivos, que praticamente esperam o tempo da aula passar. Tal situação exige uma ação efetiva do professor que, na situação registrada, não ocorreu. Com que freqüência isso acontece e como equilibrar o excesso de demanda, por parte de alguns alunos, com a falta de solicitação por parte de outros, especialmente quando esses outros são alunos passivos?

\section{Organizar um ambiente de aprendizagem é uma tarefa de design}

A tarefa de coordenar objetivos e orientações sobre como operar os dispositivos no transcurso de uma atividade é um exercício contínuo de design. Quando um professor prepara uma atividade ou um conjunto de atividades, de forma mais ou menos deliberada, ele organiza um ambiente de aprendizagem. Ele realiza uma tarefa de design que procura antecipar as próprias ações e as ações práticas dos alunos com 
os objetos do ambiente que estruturou, visando um certo objetivo. 0 engajamento, a sintonia das interações entre alunos e entre alunos e professor, mediadas por diferentes artefatos, é uma meta sempre presente.

Carrol (1993), ao discutir a relação entre ciência pura e ciência aplicada, argumenta que uma experiência de design é, simultaneamente, um contexto de investigação. A preparação de uma atividade ou de um conjunto de atividades, em uma seqüência de ensino, é também um trabalho de design e, como tal, fonte de questões de pesquisa pertinentes e relevantes.

\section{Simultaneidade das ações}

\section{Nota 2: Experimento com força centripeta}

\begin{abstract}
Enquanto Evandro, Mário e Míriam discutem o efeito da força centrípeta no vetor velocidade, Valter presta atenção em uma explicação que $o$ professor desenvolvia com outro grupo, para a questão de dois automóveis, de massas iguais e velocidades diferentes, fazendo uma curva. $E$ constata que haviam errado a resposta a essa questão. Em vão, procura chamar a atenção dos colegas para que retomem essa questão.
\end{abstract}

Esse pequeno trecho pode ser relacionado a outra descrição que mostra como o professor inicia os trabalhos explicitando a agenda da aula, o que considerava uma ação fundamental, e de como os alunos realizam uma série de ações corriqueiras, aparentando prestar pouca atenção ao que diz o professor. Ambos os relatos são uma evidência da simultaneidade das ações em uma sala de aula: alunos engajados na discussão de uma atividade, alunos dispersos discutindo outro assunto, uma rápida interrupção para uma brincadeira, o professor explicando a um grupo uma questão que desperta a atenção de um participante de outro grupo. As trocas estabelecidas são, portanto, bastante diversas e vão muito além do controle do professor. São trocas que produzem entendimento na direção dos objetivos da ativi- dade, que indicam dispersão em relação à tarefa proposta, que evidenciam dificuldades de entendimento, muitas vezes ocorridas em um instante no qual o professor não está próximo. Em relação a essa última situação, algumas vezes, o professor, tendo a oportunidade de resgatar a dúvida do grupo, não o faz por não ter a escuta adequada. Relacionamos, a seguir, outro trecho que atesta essa simultaneidade.

Nota 3: Simulações do movimento circular uniforme

[...] uma dúvida, uma dificuldade maior, que produz uma interrupção da cadeia de operações leitura da pergunta/observação da animação/resposta, os alunos recorrem aos orientadores da atividade. São dois alunos do curso de Licenciatura em Física atendendo 9 duplas. Ainda assim, não conseguem responder, de pronto, à solicitação. Tal demora força os alunos a buscarem suas próprias soluções para a questão. Esse descompasso tem conseqüências positivas, na medida em que os alunos estão engajados e a dificuldade se mantém como desafio a ser solucionado.

Relembramos aqui a dificuldade, durante a orientação de uma atividade em sala, de equilibrar o excesso de solicitações por parte de alguns grupos com a falta por parte de outros. Se, em destaque anterior, isso implicou em reforçar a passividade de uma dupla, no caso do grupo em foco, significou forçá-los a elaborar mais e de forma autônoma. São acontecimentos que se dão à revelia e sem o conhecimento do professor.

A documentação, em áudio e vídeo, das atividades de dois grupos em dois pontos distintos da sala contribuiu para nos aproximar dessa rede de interações nas quais o professor é um dos atores, não necessariamente o protagonista. 0 que, muitas vezes, é considerado ruído para se entender a gravação do diálogo entre dois alunos foi, para nós, dado de pesquisa, revelando parcialmente essa complexa teia de ações simultâneas. 


\section{Diversidade de estilos de conduta}

Nota 4: Simulações com composição de velocidades

Lucas faz os registros e emite as respostas sem questionar ou compartilhar com Danilo. Parece não valorizar as contribuições do colega. Este, por sua vez, elabora o tempo todo, demonstra mais satisfação com o ambiente e questiona os registros do parceiro quando acha pertinente. Chama para o diálogo o tempo todo, mas Lucas não realimenta o processo.

Nota 5: Simulação com composição de velocidades

Ao longo de toda a atividade, Lucio demonstra mais segurança na enunciação das respostas. Ivo se apresenta mais vacilante, como que elaborando parcialmente conceitos e relações, completando o processo com o suporte de Lucio.

Nota 6: Simulações do movimento circular uniforme

Em comparação com Lucio e lvo, Danilo e Lucas produzem mais elaborações. Quais as possíveis razões? Lucio exibe uma autoconfiança maior sobre o próprio raciocínio. Interpreta, responde e segue sem solicitar ajuda. Se ele faz elaborações incorretas ou 'pobres', é mais difícil acessá-las e debatê-las. $O$ seu parceiro não apresenta uma postura mais firme em questioná-lo. Tem menos segurança de suas idéias, talvez porque veja em Lucio uma referência de respostas certas. Caberia orientar Lucio para duvidar mais de suas respostas e Ivo para confiar mais nas próprias construções.

Danilo demonstra, por sua vez, uma atitude que pode ser tipificada: está engajado na atividade; quer aprender; está estimulado pelo ambiente; verbaliza o tempo todo sua compreensão, isto é, produz representações sistematicamente, estando sempre aberto a reelaborá-las; não hesita em solicitar ajuda ao professor. Ao mesmo tempo, não se coloca na posição de apenas acessar o modelo correto, mas dialoga com o professor a partir das elaborações que faz, procurando revê-las; questiona sistematicamente o parceiro [...] Duvida não apenas das próprias afirmações, mas também das enunciadas pelo colega.

\section{Nota 7: Experimento com força centripeta}

O grupo utiliza o dispositivo como mediação. Busca responder às questões utilizando o artefato como referência. Parece ser diferente de Lucio e Ivo. Especialmente em relação à conduta de Lucio. Este parece se haver bem com relações construidas a partir de experiências de pensamento, concatenadas de forma consistente. Parece que Lucio não sente necessidade de buscar certas evidências que seriam, em princípio, óbvias e, portanto, não demandariam observação.

Nota 8: Simulações do movimento circular uniforme

Fabrício não se preocupa em ajudar Alfredo a compreender. Dita as respostas chamando-o, 'de brincadeira', de 'animal', 'cavalo'. Alfredo, por sua vez, não apela. Quando há a oportunidade, retribui as 'gentilezas'. Isso parece não afetar nenhum dos dois. Nesses diálogos, é possivel perceber que Alfredo não compreende várias relações, porém ele não questiona Fabrício nem indaga o professor. Falta-lhe iniciativa. Ao se deparar com uma dúvida, a dupla não investe na tentativa de uma solução. Aguarda a presença do professor que chega e transmite o modelo.

As ações destacadas nas narrativas expressam uma diversidade de estilos de conduta diante das tarefas propostas. A fundamentação teórica para a afirmação da existência desses estilos e um trabalho de caracterização cuidadosa comporiam uma nova investigação. A constatação desses estilos surge da investigação sobre os etnométodos. Neste trabalho, apenas apontamos algumas caracteristicas que diferenciam os alunos e que sinalizam alguns tipos: 
- Há alunos com um estilo mais dedutivo que têm facilidade de formular hipóteses e operar de forma consistente com elas. No ambiente com experimentação, não sentem necessidade de manusear as montagens. Apenas observam. Parece que não têm dificuldade de fazer ajustes entre o observado e o esperado, com base em um certo modelo. São alunos que provavelmente tiram maior proveito de uma aula expositiva, especialmente se essa aula é dialogada, procurando estabelecer uma dinâmica de argumentação com a turma. Nesse contexto, participam mais, contribuem e colaboram para a construção das idéias que o professor quer apresentar à turma. Exibem maior confiança nas suas elaborações e tendem a ter um predomínio no grupo, talvez, por articularem e expressarem melhor as idéias;

- Há os alunos pragmáticos que acionam os meios necessários para a conclusão da tarefa proposta. Dialogam o suficiente para isso ou nem mesmo dialogam. Copiam a resposta com maior possibilidade de ser a certa. Quando chamados a expressarem suas idéias no grupo ou para a turma inteira, demonstram dificuldades, inibição e um silêncio, que termina por ser preenchido pela voz de colegas que não se contêm e respondem, ou do próprio professor, preocupado em dar um certo ritmo à aula e em transmitir o princípio, a explicação, a solução correta;

- Há os alunos interativos que se expandem em ambientes que fogem da dinâmica da transmissão. Aprendem manuseando os artefatos disponíveis, enunciando e discutindo suas idéias as dos colegas e professor. Contribuem muito para a elaboração coletiva, reforçam e evidenciam o caráter distribuído da cognição e a evolução conjunta dos parceiros de uma atividade (Salomon, 1997). Seriam aqueles alunos explicitamente 'construtivistas' que realimentam positivamente o trabalho daquele professor que acredita na importância de dar protagonismo aos alunos.

Essa diversidade de estilos, cuja caracterização apenas esboçamos, aparece junta- mente com as assimetrias nos trabalhos de grupo. Tais assimetrias levam-nos a relativizar o argumento de que os trabalhos em duplas e em grupo são a melhor estratégia para oportunizar a aprendizagem. Não necessariamente. 0 predomínio de um dos membros de uma dupla pode significar aprendizagens incompletas para um outro membro, que não consegue elaborar de forma autônoma e fica dependente de um suporte. 0 ambiente de trabalho em grupo pode ser, inclusive, agressivo e significar inibição e um fechamento à participação e ao compartilhamento das dúvidas e dificuldades. Mais uma vez, a observação, a escuta e a intervenção do professor são aspectos fundamentais para atuar nesses obstáculos e tornar o trabalho em grupo uma oportunidade real de aprender. Reconhecemos, contudo, todas as possibilidades abertas para o diálogo entre pares, como atestam os episódios discutidos em Moreira e Borges (2003).

A importância e a dificuldade do acompanhamento sistemático do professor, a simultaneidade das ações, a diversidade de estilos de conduta e de parceria tornam um ambiente envolvendo atividades em grupo bastante complexo e repleto de desafios à prática docente. Não são ambientes, que por si, redundam em oportunidades efetivas de aprendizagem. A organização desses ambientes e das atividades que neles transcorrem é uma verdadeira tarefa de design. É preciso desenvolver estratégias de acompanhamento, nas quais o professor faça escolhas de que grupos acompanhar, equilibrando o excesso e falta de solicitações, identificando e atuando sobre as assimetrias. Como aprender e ensinar tais competências?

\section{Como o livro didático comparece?}

Em outro agrupamento de narrativas, evidenciamos uma articulação bem sucedida entre simulações e livro-texto. 0 livro disponibiliza uma informação que contradiz a resposta dada a uma questão de interpretação de uma animação na tela do computador. 0 livro com- 
parece aí como um acervo de informações corretas, devidamente organizadas. Como os alunos se colocam diante do ambiente envolvendo simulações e daquele em que a fonte de questões e respostas é apenas o livro?

Nota 9: Descrição prévia à observação da atividade Experimento com força centripeta

Destaco a conversa inicial com os alunos sobre a atividade com simulações, ocorrida na semana anterior. Pelo menos metade da subturma, talvez mais, disse que prefere trabalhar com o livro a trabalhar com simulações. Segundo eles, no livro as coisas não estão prontas, tem que se pensar mais. $O$ detalhamento proporcionado pelas simulações pode gerar um falso entendimento.

No livro-texto, registros escritos e imagens/figuras estão articulados segundo uma certa lógica. 0 aluno pode 'ler' esses registros achando que está entendendo, sem o incômodo de uma questão não compreendida e não respondida. Na maioria das vezes, a representação pictórica do texto não lhe suscita explicitamente questões, a menos que ele esteja efetivamente imbuído de compreender as relações entre texto e figura/imagem propostos pelo autor.

Além de mostrar as representações com animação, as simulações disponibilizam mais ícones, todos relacionados entre si, alguns com textos sucintos articulados, como no livro, e a maior parte com questões dirigidas de interpretação. Por um lado, a oportunidade de manipular a representação em uma animação pode favorecer a interpretação e compreensão e, ainda, disponibilizar novas possibilidades de construção. Por outro, a evolução da representação no tempo, conjugada a questões, é mais um grau de liberdade a ser coordenado pelo aprendiz. Estas, para serem respondidas, obrigam a utilização dos recursos disponíveis. Ao preferirem o texto, esses alunos podem estar revelando um certo estilo de aprendizagem, mas podem estar dizendo, à sua maneira, que ficam incomodados com a complexidade da tarefa com simulações, como destacado por Lowe (2003) e Lewater (2003). Estes chamam a atenção para a possível sobrecarga cognitiva de ambientes com multimídia.

Com base no relato dos monitores do laboratório de informática, acrescentamos a seguinte análise: a informação está disponível de forma mais completa no livro e acessível a um ritmo ditado pelo aluno; as telas não apresentam toda a informação necessária, propõem questões, proporcionam um contexto em que as lacunas ficam mais evidentes, seja em relação a conhecimentos anteriores, seja em relação à compreensão da representação. Os monitores salientaram ainda que sempre que o fluxo da atividade é interrompido, boa parte dos alunos recorre ao livro didático buscando restabelecer o elo. Destacamos, portanto, um possível papel do livro nos ambientes pesquisados: acervo de informações corretas, apresentadas de forma 'completa' e estruturada, acessíveis ao ritmo do aluno.

A interação com o livro e a realimentação da atividade numa progressão contínua que se pretende ensinar, em termos de compreensão dos conteúdos, é uma possibilidade. Porém, esse mesmo acervo de informações corretas, 'completas' e estruturadas, especialmente as respostas dos exercícios, colocadas ao final dos capítulo, proporciona um outro tipo de realimentação, que se conecta a um procedimento característico das salas de aula pesquisadas e o reforça. É um procedimento também recorrente na interação entre orientador da atividade e alunos, tanto na atividade experimental quanto na atividade com simulações: transcrever a resposta certa para o roteiro ou para o relatório de atividades. A compreensão das relações trabalhadas e de seu processo de produção torna-se um elemento secundário. Isso não implica necessariamente desinteresse. Os alunos podem estar engajados na atividade, mas movidos pelo objetivo de responder aquilo que julgam ser o que o professor espera: a resposta certa, de acordo com um procedimento padrão. 
A discussão sobre a utilização do livro didático nos ambientes pesquisados envolveu a insatisfação manifestada por parte dos alunos em relação ao ambiente envolvendo simulações. Esse descontentamento sinaliza que a quebra da rotina das aulas não garante engajamento de todos. Um dos alunos fez o seguinte comentário durante uma das aulas: "Física estressa, ainda mais com computador". A hipótese da existência de diferentes estilos de conduta e a possibilidade de caracterizá-los podem ser elementos de explicação para a diversidade de preferências e motivações, apresentadas pelos alunos nos diferentes ambientes. 0 que se espera na introdução de uma atividade com computadores é que todos se interessem e participem mais. No entanto, isso não acontece.

\section{Que aspectos se destacam nessa sala de aula construída?}

Os tópicos, nos quais agrupamos os trechos de narrativa, destacam elementos de descrição de uma sala de aula, em situação de pesquisa, e contribuem para:

- uma compreensão da relação entre as ações de ensinar e pesquisar. Estas podem ser elementos constitutivos do trabalho docente, realimentando-se continuamente. A ação do professor pode acentuar um desses pólos constitutivos, mas o desenvolvimento de uma prática de ensino consistente se realiza também por uma conduta de pesquisa sistemática, ainda que não formal. Em contrapartida, a reflexão sobre o fazer docente é fonte rica de questões de pesquisa pertinentes e relevantes; - uma reflexão sobre o alcance de se explicitar uma agenda em sala de aula e de como lidar com a diferença de objetivos assumidos por alunos e professor, em uma situação de ensino;

- um questionamento acerca dos potenciais de um ambiente de trabalho em grupo, na medida em que se destacou a sua complexidade, e a rede de ações simultâneas que se concretiza, para além do controle do professor;
- uma discussão sobre as estratégias de acompanhamento dos grupos e a importância do trabalho do professor, considerando a diversidade de estilos de conduta e de motivação, as diferentes maneiras como os recursos, à disposição dos alunos, são utilizados por eles;

- a visão de que preparar uma aula ou uma seqüência de ensino, especialmente a que prevê trabalhos em grupo, é uma verdadeira tarefa de design;

- um destaque na tensão permanente entre o diálogo e a transmissão do conhecimento.

\section{A sala de aula como uma comunidade de prática}

Do ponto de vista da etnometodologia, o material empírico trabalhado requer novas aproximações para identificação e descrição mais precisas dessas ações práticas que alunos e professores desenvolvem para conferir estabilidade aos seus espaços de atuação. Entretanto, apresentamos elementos de descrição que possibilitam uma caracterização da sala de aula. Acreditamos haver caracterizado um etnométodo dessa comunidade de prática: o compromisso compartilhado por alunos e professor de produzir a explicação correta, deixando em segundo plano os meios e o processo necessários à sua concretização. Ao discutir o caráter situado da cognição, Clancey (1997) chama atenção para as suas dimensões funcional e comportamental. A dimensão funcional relaciona-se aos papéis que professor e alunos se atribuem e o do que consideram como cabível, desejável, passível de ser reconhecido dentro de uma determinada comunidade. Esse compromisso é um aspecto importante da coreografia do fazer em sala de aula. A dimensão comportamental refere-se à percepção do que faço agora e dos efeitos de minha ação, modificando o que faço em seguida.

Do ponto de vista funcional e comportamental, há uma realimentação mútua entre alunos e professor, reforçando a explicitação da resposta certa. A pergunta que os alunos fazem 
ao professor não recupera a rica discussão que precedeu sua chegada. A escuta do professor e sua intervenção também não efetivam esse resgate. Conceitos e relações são, então, enunciados de forma pretensamente clara, estruturada. Os alunos se esforçam para fazer o registro da forma enunciada pelo professor. Uma oportunidade de aprendizagem é pobremente explorada. Quando algum membro do grupo quebra o ritmo dessa coreografia, reafirmando suas convicções, chamando para o debate colegas e professor, ficam evidenciados a força da interação e do diálogo na construção do conhecimento.

A coreografia de 'fazer conforme o modelo' e de 'produzir a explicação e a resposta corretas' determina a forma como os diferentes artefatos, presentes em cada ambiente - simulações, livro didático, experimento - são utilizados pelos alunos. A identificação dessa coreografia suscitou o questionamento sobre as razões que a sustentam e a realimentam na dinâmica das interações em sala de aula. Com base na experiência docente do relator desta pesquisa, uma das razões pode decorrer da meta de cumprir o programa estabelecido para uma aula, para uma etapa, para o ano letivo. Nessa perspectiva, o tempo, como um aspecto da organização e do desenvolvimento do trabalho, adquire protagonismo e realimenta continuamente a tensão entre diálogo e transmissão.

Essa tensão é inerente à prática de sala de aula. Pode ser produtiva, no sentido de dar ritmo ao trabalho, de impulsionar progressos, de preencher lacunas que geram novos problemas e realimentam o diálogo. Porém, pode também calar a voz do aluno, impedir elaborações mais ricas do ponto de vista individual e coletivo. Pode impedir o aproveitamento de situações potenciais de aprendizagem. Administrar produtivamente essa tensão é uma competência a ser buscada, continuamente, em nosso desenvolvimento profissional como professores. Implica buscar clareza de objetivos e capacidade de redefini-los permanentemente.

Outro elemento característico dos ambientes pesquisados é a simultaneidade de ações, dramaticamente acentuada quando o ambiente é estruturado com base na realização de atividades em grupo. 0 reconhecimento dessa simultaneidade implica na consciência dos limites de nossa intervenção como professores, ao mesmo tempo em que ressalta sua importância. Os acontecimentos simultâneos desenrolam-se para muito além do controle docente. Não é possível acompanhar, com eficácia, todos os grupos. Para alguns, de fato, uma distância maior do professor pode significar momentos de progresso na capacidade de argumentação e de uma aprendizagem autônoma. Outros grupos, que não solicitam a presença do professor, são aqueles em que a presença dele é mais importante. Sobretudo uma presença que saiba ouvir, que saiba identificar o que emperra o progresso do grupo. Ciente da diversidade de estilos e motivações, atuar positivamente sobre a passividade dos alunos é um desafio à prática do professor.

Acompanhar os trabalhos de grupo começa, então, pela arte de fazer escolhas em meio ao excesso e à falta de demandas, em meio a condutas autônomas e às dependentes de um suporte, em meio à participação e à passividade. 0 ambiente de atividades em grupo não é necessariamente um ambiente favorável à aprendizagem. Depende do design da atividade e, sobretudo, da intervenção sistemática e inclusiva do professor. Expressa uma dinâmica complexa, retratada pela simultaneidade e diversidade de ações.

De Sá e Borges (2001) investigaram a compreensão que os alunos expressam dos objetivos de uma atividade prática em um ambiente de experimentação. Segundo seu estudo, a maior parte dos alunos não apreende os objetivos propostos pelo professor no início da atividade. No entanto, isso não impede o desenvolvimento da atividade pelos alunos. A partir de diálogos entre alunos e professor, esses autores mostram que a compreensão dos objetivos propostos evolui no transcurso da atividade. Na medida em que o professor interage com os alunos, tendo clareza dos objetivos que quer 
atingir e fazendo as abordagens de forma adequada, estes, que não demonstraram compreensão dos objetivos no início da atividade, não apenas realizam essa compreensão como dão indicadores de que os objetivos propostos foram alcançados. Esse resultado do trabalho de De Sá e Borges dirige o nosso olhar de uma forma diferente para as descrições que mostram a distância entre o que é importante para o professor, no início de uma atividade, e no que estão ligados os alunos ou o que eles apreendem inicialmente. Nossas descrições e essa compreensão dos objetivos, em processo, destacada por De Sá e Borges, relativizam os efeitos de explicitar a agenda no início de cada aula. Continuamos acreditando na importância dessa ação, mas ela deve estar sintonizada com uma concepção expressiva de objetivos e atividades, destacada por Madaus e Kellaghan (1992) e Nespor (2001).

Madaus e Kellaghan discutem a proposição de se trabalhar com objetivos 'expressivos' (Eisner, 1969), que não especificam os resultados do ensino da mesma forma que os objetivos instrucionais. De outro modo, os objetivos expressivos são usados para descrever 'um encontro educacional' no contexto da realização de uma atividade ou da solução de um problema. Nespor (2001) afirma que o objetivo instrucional é prescritivo e a atividade instrucional é uma prescrição do que será necessário para realizálo. A atividade expressiva não é prescritiva, mas evocativa. Ela não busca antecipar um tipo particular de resposta. Em vez disso, ela objetiva construir um encontro, criando um ambiente ou formando uma situação que estimulará respostas e soluções dos estudantes diversas e amplamente não antecipadas.

Essa formulação opõe duas concepções de objetivo. Nossas descrições da sala de aula destacam a complexidade desse ambiente e a existência potencial de todo tipo de obstáculos a iniciativas, que flexibilizam ou rompem com estratégias de transmissão do conhecimento. A estruturação e realização de atividades expressivas, conforme propostas por Eisner (1969), caracterizam uma situação ideal que deve ser buscada por aproximação. Acreditamos na estratégia de perseguir, inicialmente, objetivos mais modestos, considerando um conjunto de limites ao exercício dessa concepção expressiva de atividade e objetivo. Tal exercício remete-nos à postura do professor em relação aos objetivos que direcionam sua ação. Acreditamos que ela deve ser uma postura de flexibilidade e evocativa. Isso reforça também a importância de se negociar permanentemente as evidências produzidas em um ambiente de experimentação. Os resultados desta investigação salientam a necessidade de, como professores, reconhecermos a impossibilidade de controle sobre o que elabora o aluno. Não só reconhecer, mas valorizar e tirar proveito desse aspecto inerente da aprendizagem. Nessa perspectiva, alcançar um objetivo implica a modificação do que foi inicialmente proposto, ainda que o inicialmente proposto tenha sido feito de forma prescritiva.

Completa, finalmente, essa síntese dos elementos de descrição da prática de sala de aula, a diversidade de estilos de conduta e de motivações. Obtivemos evidências dessa diversidade. Do ponto de vista situado da cognição, a caracterização desses estilos implicaria possivelmente na proposição e tentativa de responder a questões como: qual a coreografia de cada estilo? 0 que o aluno valoriza e que papel atribui a si? Que papel atribui ao professor? Que condutas considera desejáveis na comunidade prática da sala de aula? Acreditamos que a estruturação e articulação de diferentes ambientes de aprendizagem e o registro em áudio e vídeo das ações, nesses diferentes ambientes, contribuíram para evidenciar a diversidade de estilos. Isso reforça a importância de o professor tentar estruturar um curso que proporcione diferentes ambientes de aprendizagem.

Diversificar os ambientes de aprendizagem favorece que todos os alunos 'entrem na roda', produzam e aprendam conhecimento físico, dentro de uma dinâmica com a qual se identifiquem mais. Nossa aposta é que, ao par- 
ticipar de um ambiente onde se sinta bem, expressando e desenvolvendo seus potenciais de aprendizagem, o aluno se abra para o restante da programação proposta em um curso de física. Aquela expressão 'odeio física' pode estar fundada no sentimento permanente de fracasso e na sensação, por parte do aluno, de que não é capaz de aprender nada dessa área de conhecimento.

\section{É preciso reconhecer e conhecer os limites}

A sistematização de elementos de descrição da sala de aula nos aproxima, por um lado, de conclusões propostas por Roth, Bowen e McGinn (1999) quando afirmam que objetivos de aprendizagem, como aprender a interpretar gráficos, devem ser analisados no contexto de uma prática social. Por outro, coloca-nos a questão de que prática social focalizar. Roth e colaboradores entendem que os recursos de interpretação não devem ser ensinados aos estudantes de forma independente de interpretações de situações reais. Afirmam que os estudantes precisam participar de atividades que thes possibilitem melhorar a competência de interpretar gráficos e desenvolver recursos de interpretação acessíveis por meio de práticas científicas mais autênticas. Propõem, portanto, focalizar a prática científica como prática social e buscar formas de fazer a transposição de elementos dessa prática para o fazer da sala de aula.

Esse seria um tipo de resultado de pesquisa que demandaria, possivelmente, alterações significativas na maioria das salas de aula de física. Entretanto, perguntamos: como estruturar ambientes de trabalho científico autêntico na sala de aula em meio a limites característicos desse lugar?

Ao discutir como as reformas curriculares têm incidido sobre a prática docente, Mortmer (2002) aponta a necessidade de se pesquisar como o professor se apropria de diferentes elementos das novas propostas curriculares. Apresenta resultados de uma pesquisa que mostra que no discurso do professor há uma tensão entre apropriação e resistência. Ainda que essa tensão se expresse com a predominância de um ou outro pólo, ela evidenciaria que o professor sempre se apropria de aspectos das inovações curriculares a partir de sua prática e seu discurso atuais. Tal resultado indicaria ainda que há uma interação dialógica do professor com esses movimentos de mudança.

Considerando o cenário da sala de aula construído na investigação aqui relatada, entendemos que essa tensão entre apropriação e resistência deve ser compreendida também a partir das dificuldades objetivas que o professor enfrenta na organização de qualquer ambiente de aprendizagem. Com base em estudo desenvolvido sobre o caráter complexo das inovações educacionais, Moreira (2003) afirma que qualquer que seja a abordagem escolhida, ela terá de lidar com as tensões transmissão $x$ construção, educação para todos $x$ formação específica e aprofundada, avaliação processual $x$ avaliação de fim de processo, estabelecimento de ritmos médios $x$ tratamento das diferenças, princípios gerais de uma disciplina $x$ abordagem integrada e contextualizada. Em que medida essas tensões dificultam, por exemplo, a transposição do fazer científico autêntico para o contexto da escola?

Respostas a essa pergunta dialogam com a questão proposta no início desse trabalho: o que a pesquisa em educação em ciências já produziu até o momento que auxilia os professores em sala de aula ou os formuladores de políticas educacionais a tomar decisões práticas reais? Para que esses resultados de pesquisa possam de fato auxiliar o professor, a prática que ocorre no interior da sala de aula e da escola deve ser estudada como uma prática social, com características próprias, e que impõe obstáculos à efetivação de mudanças. Nesse trabalho, salientamos alguns desses obstáculos e a necessidade não apenas de reconhecê-los, mas especialmente de conhecê-los com mais profundidade. Esse tipo de conhecimento poderá se constituir em subsídio importante para que o professor reflita sobre sua prática e participe de um processo contínuo de desenvolvimento profissional, que 
incidirá sobre o seu fazer docente, aperfeiçoandoo e qualificando-o. 0 esforço de descrição que fizemos objetivou contribuir para esse diálogo.

Os resultados da pesquisa em educação em ciências que apontam a necessidade de revisão da prática de ensino atualmente vigente sinalizam a abertura de muitas possibilidades e de um ensino mais formador e com mais significado para o aluno. 0 trabalho de Roth e colaboradores juntamente com as propostas de desenvolvimento curricular fundadas na construção e solução de problemas abertos podem ser citados como exemplo. Porém, insistimos que as condições objetivas da sala de aula e a prática que nela se realiza colocam obstáculos que, se não considerados, estudados e conhecidos, poderão afastar esse diálogo do fazer docente com a pesquisa para espaços educativos pouco representativos das decisões, do que pode ser feito, do que efetivamente se faz no âmbito do ensino de ciências e de física, especialmente na educação média. 0 diálogo com o fazer autêntico da ciência, por exemplo, é sem dúvida uma fonte rica de revisão e adequação dos nossos objetivos e práticas de ensino. No entanto, esse diálogo deve ser construído com os pés no chão... no chão da sala de aula... no chão da escola.

\section{Referências bibliográficas}

CARROL, J. Desingning Interaction: psychology at the human-computer interface. Cambridge: Cambridge University Press, 1993.

CLANCEY, W. J. Situated Cognition: on human knowledge and computer representation. New York: Cambridge University Press, 1997.

COULON, A. Etnometodologia e educação. In: FORQUIN, J.C. (Org.) Sociologia da Educação: dez anos de pesquisa. Trad. Guilherme João de Freitas Teixeira. Petrópolis: Vozes, 1995. cap.6, p. 300-349.

De SÁ, E.; BORGES, 0. Como alunos e professores entendem o propósito de uma atividade de laboratório. In: ENCONTRO NACIONAL DE PESQUISA EM EDUCAÇÃO EM CIÊNCIAS, 3., 2001. Atibaia, S.P. Atas... (arquivo de computador) Porto Alegre: s.n., 2001.

EISNER, E. W. Instructional and expressive educational objectives: their formulation and use in curriculum. In: POPHAM, W. J. et al. (Ed.) Instructional Objectives. AERA Monograph Series on Curriculum Evaluation 3. Chicago: Rand McNally, 1969.

HOLSTEIN, J.A.; GUBRIUM, J. F. Fenomenologia, etnometodologia e prática interpretativa . In: DENZIN, N. K.; LINCOLN, Y. S. (Ed.) Handbook of qualitative research. London: Sage Publications, 1994. p. 262-272.

LOWE, R. K. Animation and learning: selective processing of information in dynamic graphics. Learning and Instruction, v. 13, p. 157-176, 2003. Disponível em http://www.elsevier.com/locate/learninstruc. Acessado em 27/08/2003.

MADAUS, G. F.; KELLAGHAN, T. Curriculum evaluation and assessment. In: JACKSON, W. P. (Ed.) Handbook of research on curriculum. New York: Simon \& Schuster Macmillan, 1992. p. 119-154.

MOREIRA, A. F. Práticas de interpretação em ambientes de aprendizagem de física. 2003. Tese (Doutorado)- Universidade Federal de Minas Gerais, Belo Horizonte, 2003, 180p.

MOREIRA A. F.; BORGES, 0. N. Interpretação de representações dinâmicas. In: ENCONTRO NACIONAL DE PESQUISA EM EDUCAÇÃO EM CIÊNCIAS, 4., 2003: Bauru, S. P. Atas... (arquivo de computador) Porto Alegre: s.n., 2003.

MORTMER, E. F. Uma agenda para a pesquisa em educação em ciências. Revista Brasileira de Pesquisa em Educação em Ciências. v. 2, n. 1, p. 25-35, jan./abr. 2002.

NESPOR, J. S. Ethnografic methods in educational research. 2001. Disponível em http://www.tandl.vt.edu/nespor/653401.html. 
ROTH, W-M.; BOWEN, G. M.; McGINN, M. K. Interpretation of graphs by university biology students and practicing scientists: toward a social practice view of scientific representation practices. Journal of Research in Science Teaching, s.l., v. 36, n. 9, p. 1020-1043, 1999.

SALOMON, G. (Ed.) Distributed cognitions: psychological and educational considerations. Cambridge University Press: 1997. cap. 4. p. 111-138.

SCHÖN, D. A. Educating the reflective practitioner. San Francisco: Jossey-Bass Publishers, 1987.

Recebido em 30.05.05

Aprovado em 15.09.05

Adelson Fernandes Moreira é professor de Física da Coordenação de Ciências e do Programa de Pós-Graduação em Educação Tecnológica do CEFET-MG. Licenciado em Física pela UFMG. Doutor em Educação (FAE-UFMG).

Oto Borges é professor de Física do Colégio Técnico da UFMG e do Programa de Pós-Graduação em Educação da FAE-UFMG. Bacharel em Física pela UFMG. Doutor em Física (ICEX, UFMG). 